\title{
PEMANFAATAN MEDIA DISPLAY PADA PROSES PEMBELAJARAN
}

\author{
Muhammad Ullil Fahri \\ Muhammad.fahri001@binus.ac.id \\ https://ullilfahri.skb.ovh/
}

\section{A. MEDIA DISPLAY}

Media pajangan (Display) merupakan media yang digunakan untuk memajang gambar, kartu, poster dan benda kecil tiga dimensi atau materi pendidikan lainnya [1]. Dalam hal ini penunjang visualisasi merupakan agar dapat dilihat langsung oleh siswa. Peserta didik diajak untuk ikut berpartisipasi dalam pengamatan suatu media display baik itu dalam bentuk gambar, poster atau objek 3 dimensi lainya. Berikut adalah contoh dari media display yang dapat diterapkan [2] :

1. Flip Chart

Flip chart merupakan media yang sudah lama digunakan dalam metode pembelajaran di setiap variasi penyajiannya.

2. Papan Buletin / Bulletin Board

Papan pesan (papan buletin / board ) adalah papan pengumuman yang berfungsi untuk menginformasikan kepada orang-orang tentang acara, acara, pengumuman penting dengan konten dan konteks yang jelas.

3. Grafik

Bagan ( Grafik ) adalah gambar yang menampilkan data berupa angka dalam bentuk visual simbolik yang biasanya berasal dari tabel yang telah dibuat. Bagan ini menggambarkan hubungan masalah dengan simbol angka / persentase.
Berikut Penjelasan rinci dari media display :

\section{Media Pembelajaran Flip Chart [3]}

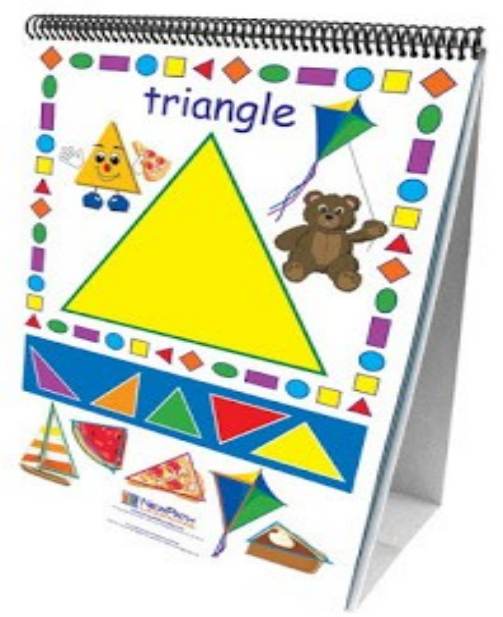

Gambar 1. Contoh Flip Chart

Pada gambar 1 merupakan contoh media penggunaan Media Display Flip Chart. Flip chart hanyalah selembar kertas seperti lembar memo atau kalender yang berukuran $50 \times 75 \mathrm{~cm}$ atau lebih kecil dari 21 x $28 \mathrm{~cm}$ [3]. Berikut adalah video contoh penerapan Flip Chart yang dapat di akses pada tautan berikut https://bit.ly/3pdi5v8 [4]. 


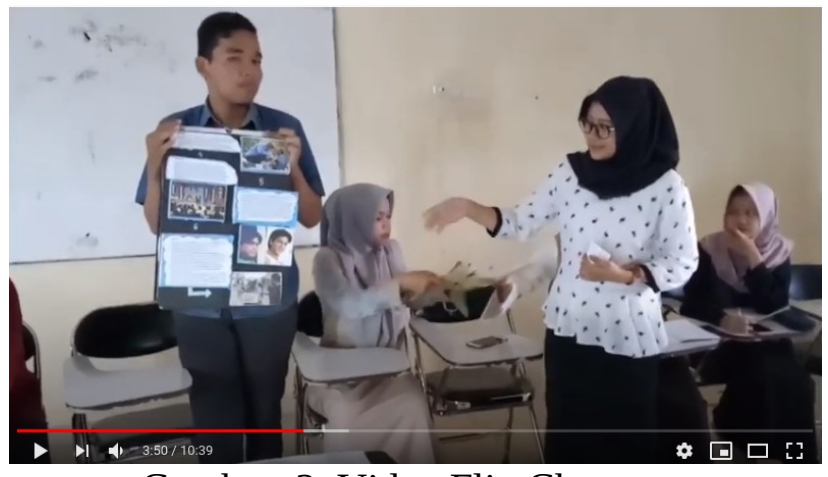

Gambar 2. Video Flip Chart

Dari gambar 2 merupakan contoh dari penggunaan media display yang berupa flipchart. Pengertian media flip chart menurut para ahli [3]:

1. Pendapat Praptono (1997, hlm. 36) yang menurutnya flipchart adalah "penyangga dua dimensi yang dapat diproyeksikan, terdiri dari lembaran kertas yang disusun saling tumpang tindih dan salah satu sisi pendek di atas diblokir pada bingkai dengan kaki

2. Menurut Hosnan (2014, hlm. 115) flip chart adalah "lembaran kertas dengan ukuran yang cukup besar agar dapat dilihat bersama-sama”

3. menurut Sudjana dan Rivai (2002, hlm. 27) flip chart adalah "kombinasi antara media grafis dengan gambar foto yang dirancang untuk memvisualisasikan secara logis dan teratur mengenai fakta dan batasan”.

Secara umum dari pendapat diatas dapat diartikan media display menggunakan flip chart merupakan sebuah media pembelajaran yang merupakan alat penunjang proses pembelajaran yang dapat diakses ( dilihat ) oleh peserta didik secara langsung.

Menurut Praptono (1997, hlm. 34) Sarat dalam pembuatan media flip chart seperti berikut [3] :

1. Ukuran kertas cukup besar dan gambar serta huruf terbaca.
2. Visualisasi ide dan pesan mudah dipahami.

3. Penampilan cukup menarik atau atraktif.

4. Komposisi warna yang serasi dan seimbang dengan luas kertas.

5. Kemudahan penggunaan, penyimpanan dan pemeliharaan.

6. Awet untuk dipakai berkali-kali dan awet.

7. Mudah dan sederhana untuk diproduksi.

Kriteria dari sebuah media menurut Sadiman (1986, hlm. 85) Seperti berikut [1] :

1. Sesuai dengan tujuan yang ingin dicapai.

2. Karakteristik siswa.

3. Strategi belajar-mengajar.

4. Organisasi kelompok belajar.

5. Alokasi waktu dan sumber.

6. Prosedur penilaian.

Dari kriteria diatas menunjukan dalam pembuatan sebuah media pembelajaran tidak bisa asal buat saja. Harus di perhatikan unsur unsur yang telah disebutkan diatas.

Arsyad (2006, p. 91) berpendapat bahwa "cara untuk menarik perhatian ke media adalah warna, huruf dan kotak". Warna digunakan sebagai pedoman dan memperhatikan informasi penting, misalnya kata kunci dapat ditekankan dengan warna-warna cerah. Huruf tebal atau huruf miring menggarisbawahi kata kunci atau judul. Informasi penting juga dapat ditekankan dengan menggunakan kotak. Penggunaan garis bawah sebagai alat panduan sedapat mungkin dihindari karena membuat kata sulit untuk dibaca [1].

Kelebihan menggunakan Flip Chart seperti berikut [5] :

1. Dapat digunakan dalam metode pembelajaran inovatif apa pun

2. Bisa lebih praktis

3. Dapat melakukan pembelajaran di lingkungan terbuka yang jauh dari listrik.

4. Bisa dibawa kemana saja tergantung lokasi presentasi 
5. Dapat menghemat media pembelajaran

6. Agar siswa tidak bosan sehingga siswa lebih berimajinasi dalamm engembangkan gagasannya

7. Mempermudah untuk mengingat topik yang telah diajarkan

8. Dapat lebih fleksibel, guru / pembaca dapat memutuskan kapan akan menulis

9. Biayanya rendah

Selain memiliki Kelebihan, penggunaan media flip chart juga memiliki kelemahan [5] :

1. Sulit dibaca karena keterbatasan yang berupa tulisan

2. Kertas flip chart hanya digunakan sekali saja

3. Peserta yang kadang banyak kadang sedikit

\section{Papan Buletin / Bulletin Board}

Menurut Sastromiharjo (2008: 10) Papan Buletin adalah papan buletin yang mengkomunikasikan atau menjelaskan ilmu pengetahuan dari sumber kepada penerimanya dengan kombinasi gambar dan tulisan suatu peristiwa dengan bentuk dan warna yang menarik. Gambar, tulisan, sketsa, diagram dan grafik dapat digunakan sebagai materi konten pada papan buletin. Ciri-ciri material siklus air membutuhkan suatu sarana yang dapat menjelaskan gambaran siklus keberadaan air di bumi. Papan pesan (buletin) membantu siswa memahami materi siklus air dengan melihatnya secara visual, dan guru dapat merangkum materi siklus air secara sederhana melalui gambar dan tulisan [6].

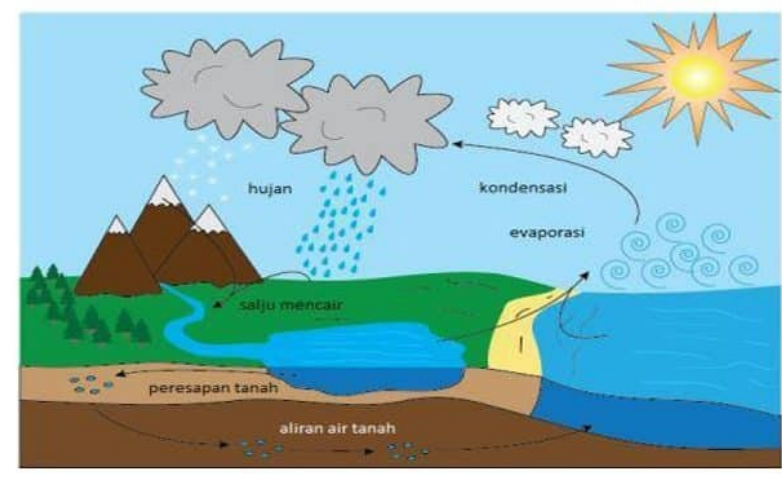

Gambar 3. Contoh Papan Buletin Siklus Air

Pada gambar 3 merupakan contoh dari gambar siklus air. Dengan adanya gambaran tersebut diharapkan peserta didik dapat melihat secara langsung kejadian alam.

Papan buletin adalah papan buletin khusus yang digunakan untuk memajang contoh hasil karya siswa, gambar, grafik, poster, dan benda dalam bentuk tiga dimensi. Biasanya berukuran 160 x $80 \mathrm{~cm}$. Papan pengumuman sering ditempatkan di koridor, kantin dan kantor, tetapi tempat utamanya adalah di ruang kelas [7]. Papan buletin lebih diutamakan dari sisi peserta didik. Dalam hal ini dengan tujuan tugas - tugas siswa yang telah dikerjakan dalam bentuk visual dapat dilihat secara terus menerus sehingga menimbulkan sugesti pemahaman secara langsung.

Tujuan Pembuatan papan buletin seperti berikut [7] :

1. Meningkatkan minat siswa dalam belajar dan pekerjaan (karya) siswa

2. Untuk menyatukan semangat kelas

3. Mendorong siswa untuk berkarya dan menciptakan produk, berinisiatif memecahkan masalah

4. sarana yang kompeten

Terdapat pengaruh yang signifikan penggunaan media pembelajaran papan buletin terhadap hasil belajar siswa pada mata pelajaran Pendidikan Kewarganegaraan di SMP Negeri 10 Palembang [8] . Dari penelitian di atas dapat dilihat penggunaan media buletin dapat mempengaruhi hasil belajar siswa. 
Berikut Langkah-langkah Penerapan Media Pembelajaran Bulletin Board [8] :

1. Guru menguasai materi ajar yang akan dikirimkan (disampaikan ke siswa)

2. Guru mengatur posisi siswa dengan satu cara diskusi atau individu

3. Guru memperkenalkan topik dan tanyakan beberapa pertanyaan ke siswa.

4. Guru memperkenalkan media dan memberikan informasi yang cukup tentang bagaimana menggunakannya

5. Guru menawarkan kesempatan kepada siswa untuk memberikan jawaban atau komentar terhadap materi Jawab pertanyaannya

6. Guru mewajibkan siswa untuk aktif, salah satunya dengan meminta siswa untuk maju menjawab dengan menempelkan jawaban yang dikemukakan guru pada papan buletin.

7. Guru menyimpulkan materi buletin media bersama-sama

Kekurangan Bulletin board [8] :

1. Mempermudah orang lain untuk mengeluarkan ( mengoyak / membuang ) informasi yang ditempel di papan buletin, baik sengaja maupun tidak sengaja, padahal informasi tersebut penting atau masih dibutuhkan.

2. Mempermudah orang lain untuk mencoret-coret atau mencoret-coret menjadi gambar atau tulisan, sehingga merusak keindahan gambar atau informasi yang terpampang di papan tulis.

\section{Media Grafik Dalam Pembelajaran}

Macam-macam Media Pembelajaran Visual

Grafik [9] :

1. Grafik Garis

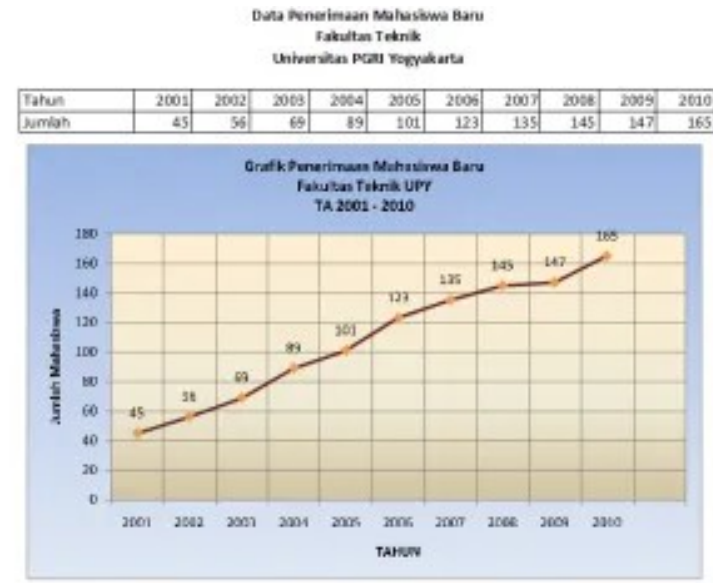

Bagan (grafik) garis adalah yang paling sesuai dari semua jenis bagan, terutama untuk merencanakan tren atau menghubungkan dua kumpulan data.

\section{Grafik batang}

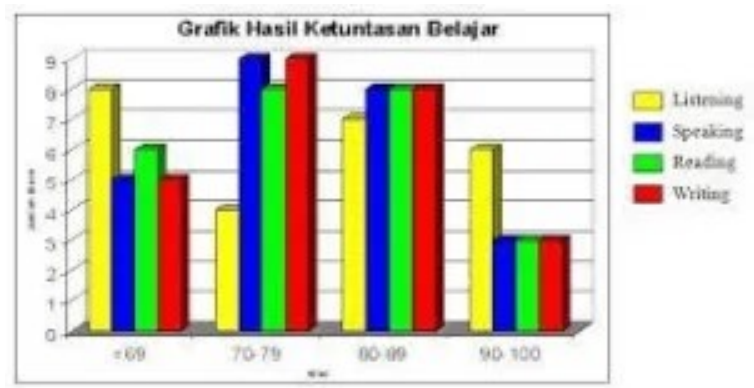

Bagan batang mungkin yang paling sederhana dari semua jenis bagan, bagan batang sangat mudah dibuat.

3. Grafik lingkaran atau piring

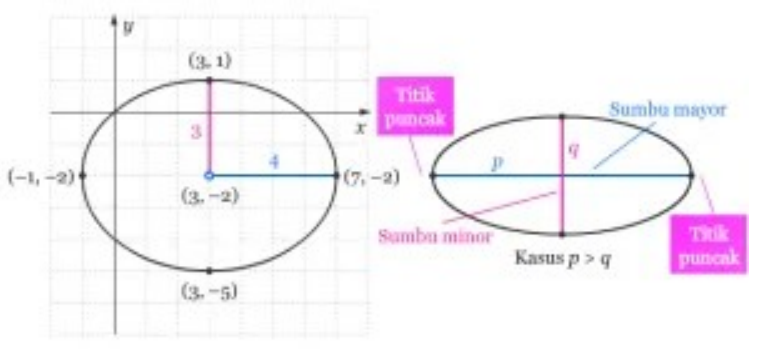


Diagram lingkaran atau diagram pelat adalah lingkaran sektor yang digunakan untuk menggambarkan bagian-bagian dari keseluruhan.

4. Grafik wilayah dan grafik gambar

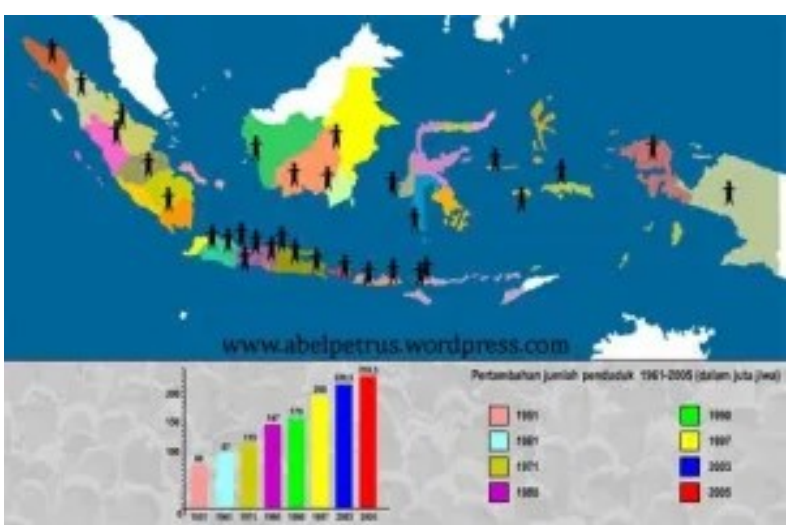

Bagan area, dalam bentuk persegi, lingkaran, dan bentuk tidak beraturan, terkadang digunakan untuk membandingkan dua atau tiga hubungan secara keseluruhan

5. Grafik gambar

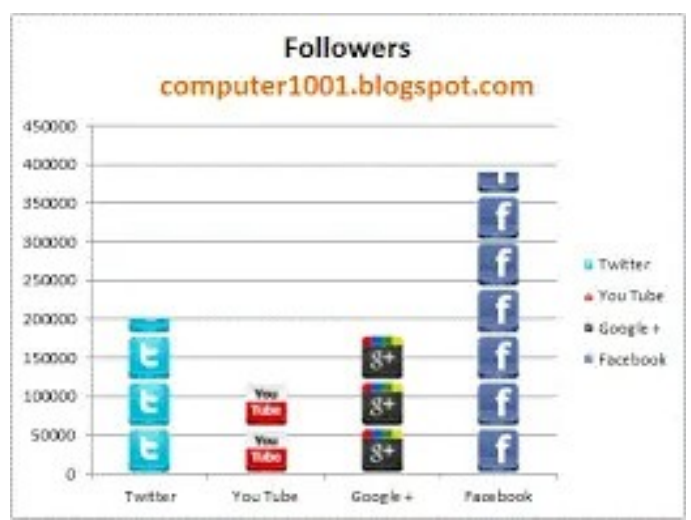

Banyak penampakan menarik mata berupa dimensi yang didapat dari warna-warna datar, bentuk sederhana dan bergambar melalui grafik grafis.

Grafik ditampilkan dengan bantuan objek berupa garis, batang, dan gambar. Menampilkan pesan dalam bentuk seperti itu memudahkan siswa dalam mengaplikasikan informasinya. Apalagi jika foto-foto tersebut sebelumnya sudah dikenali oleh para siswa. Grafik paling baik digunakan dalam materi pembelajaran berupa ringkasan pelajaran setelah siswa memperoleh informasi lain dari berbagai sumber, buku atau penjelasan sebelumnya dari guru sendiri. [10]. Grafik paling mudah ditetapkan, apalagi sekarang sudah banyak software pendukung yang dapat dengan mudah membuat sebuah grafik. Bisa kita ambil contoh software dari microsoft excel dan libre office calc.

Pengertian Grafik menurut ahli, diantaranya adalah sebagai berikut [11] :

1. Wai \& Kaicher (1976: 1) menyatakan bahwa pengertian grafik adalah suatu gambar yang tersusun dari titik dan garis yang menghubungkan titik-titik tersebut.

2. Wilson (1998: 8) menyatakan bahwa grafik adalah garis horizontal dan vertikal yang menghubungkan dua titik.

3. Selby (1979: 13) menyatakan bahwa grafik adalah alat untuk mengungkapkan dua atau lebih jenis data.

4. Harper (1988: 42) menyatakan bahwa pengertian grafik adalah suatu alat untuk memvisualisasikan data dalam bentuk garis atau kurva yang menghubungkan satu variabel dengan variabel lainnya. 


\section{DAFTAR PUSTAKA}

[1] Ismail, “MEDIA DISPLAY \& REALIA,” 2015.

https://fdokumen.com/document/pemanfaatan-media-display-realia-55888b86adaa2.html (accessed Nov. 07, 2020).

[2] Y. Ramadani, “Sebutkan contoh media display??,” 2016. https://brainly.co.id/tugas/8707519 (accessed Nov. 09, 2020).

[3] R. S. Nugraha, "Media Pembelajaran Flip Chart.” https://www.tintapendidikanindonesia.com/2017/12/media-pembelajaran-flip-chart.html (accessed Nov. 09, 2020).

[4] “FLIPCHART (media tradisional) BELAJAR DAN PEMBELAJARAN,” 2019. https://www.youtube.com/watch?v=JIh2js48tDg\&t (accessed Nov. 09, 2020).

[5] Marlina, “Flip chart adalah,” 2020. https://penaindo.com/flip-chart-adalah/ (accessed Nov. 09, 2020).

[6] D. S. D. Pratiwi, "PENGARUH MEDIA PAPAN BULETIN TERHADAP HASIL BELAJAR IPA MATERI SIKLUS AIR SISWA KELAS V SDN PACARKELING VI SURABAYA TAHUN PELAJARAN 2017/2018,” JPGSD, 2018.

[7] H. Biruni, "Pengembangan media papan flannel dan papan buletin dalam Pembelajaran PAI," 2015. https://www.slideshare.net/HofurBiruni/pengembangan-media-papan-flannel-danpapan-buletin-dalam (accessed Nov. 09, 2020).

[8] S. A. W. Septi Rotari, Emil El Faisal, "PENGARUH PENGGUNAAN MEDIA PEMBELAJARAN BULLETIN BOARD TERHADAP HASIL BELAJAR SISWA PADA MATA PELAJARAN PENDIDIKAN KEWARGANEGARAAN DI SMP NEGERI 10 PALEMBANG.”

[9] M. N. Abid, “Macam-macam Media Pembelajaran Visual Grafik,” 2017. https://dosenmuslim.com/pendidikan/macam-macam-media-pembelajaran-visual-grafik/ (accessed Nov. 09, 2020).

[10] “TEORI DAN PRINSIP PENGEMBANGAN MEDIA GRAFIS.” https://lmsspada.kemdikbud.go.id/pluginfile.php/59346/mod_resource/content/4/ PENGEMBANGAN MEDIA GRAFIS.pdf\#: :text=Nana Sudjana dan Ahmad Rifai,-kata dan gambar-gambar. (accessed Nov. 09, 2020).

[11] "Pengertian Grafik Lengkap Contoh, Jenis, Tujuan Dan Fungsi.” 
http://www.markijar.com/2018/07/pengertian-grafik-lengkap-contoh-jenis.html (accessed Nov. 09, 2020). 